\title{
Num relance de olhar... a estigmatização das pessoas gordas: do passado aos dias de hoje
}

Silvana da S. Campos, ${ }^{1}$ Francisco R. Ferreira, ${ }^{1 *}$ Cristiane M. Seixas, ${ }^{1}$ Shirley Donizete Prado, ${ }^{1}$ Maria Claudia da V.S. Carvalho, ${ }^{1,2}$ Fabiana B. Kraemer ${ }^{1}$

\section{Resumo}

Considerando o atual panorama epidêmico do excesso de peso e da obesidade no Brasil, o artigo pretende analisar como a adoção de uma visão transdisciplinar permite trazer à tona o processo em curso de moralização e estigmatização do qual são alvo as pessoas que se encontram acima peso corporal ideal. Buscamos a aproximação ao tema pela via da subjetividade a partir da compreensão dos sentidos associados ao corpo ao longo da história discutidos por Georges Vigarello e do conceito de estigma apresentado por Erving Goffman para apontar a crescente responsabilização e culpabilização do indivíduo. Algumas implicações sociais, políticas e econômicas desse fenômeno também são expostas.

Descritores: Obesidade; Moral; Estigma social; História; Peso corporal; Política.

\begin{abstract}
A glance... the stigmatization of fat people: from the past to the present day

Considering the current epidemic situation of overweight and obesity in Brazil, the article aims to analyze how the adoption of a transdisciplinary vision allows bringing up the ongoing process of moralization and stigmatization that affects people who find themselves above ideal body weight. We use subjectivity as perspective to approach the subject and understand the meanings associated with body throughout history as it is discussed by Georges Vigarello and stigma concept presented by Erving Goffman to point the increased accountability and culpability of the individual, as well as some social, political and economic implications of this phenomenon.
\end{abstract}

Keywords: Obesity; Morale; Social stigma; History; Body weight; Politics.
1. 1. Programa de Pós-Graduação em Alimentação, Nutrição e Saúde. Instituto de Nutrição. Universidade do Estado do Rio de Janeiro.

2. Programa de Pós-Graduação em Nutrição. Instituto de Nutrição Josué de Castro. Universidade Federal do Rio de Janeiro.

"Endereço para correspondência:

São Francisco Xavier, 524. 12 andar

Rio de Janeiro, RJ, Brasil. CEP: 20550-900

E-mail: chico.romao@yahoo.com.br

Revista HUPE, Rio de Janeiro, 2015;14(3):90-96

doi: 10.12957/rhupe.2015.19951

Recebido em 19/03/2015. Aprovado em 23/07/2015.

\section{Resumen}

Una mirada... la estigmatización de la gente gorda: desde el pasado hasta nuestros días

Considerando la situación actual de la epidemia del exceso de peso y obesidad en Brasil, este artículo pretende analizar cómo la adopción de una visión interdisciplinaria permite evidenciar el proceso continuo de moralización y estigmatización que las personas que están arriba del peso corporal ideal son el centro de la atención. Con este texto hacemos una primera aproximación al tema a través de la subjetividad. Nos utilizamos de la comprensión de los significados asociados con el cuerpo a lo largo de la historia desde una perspectiva como de Georges Vigarello y del concepto de estigma presentado por Erving Goffman para indicar una creciente responsabilidad y culpabilidad de la persona. Señalamos también algunas de las implicaciones sociales, políticas y económicas de este fenómeno.

Palabras clave: Obesidad; Moral; Estigma social; Historia; Peso corporal; Política. 


\section{Introdução}

Nos dias atuais, o excesso de peso, considerado um importante fator de risco para várias doenças crônicas não transmissíveis, é tido como um dos principais partícipes do processo de mortalidade em escala global. O envelhecimento da população e a obesidade geram perspectiva de grande impacto no financiamento do setor público de saúde brasileiro. Desenha-se um panorama de futuro que sugere importante tensão na relação entre os fenômenos que se interligam como profunda desigualdade social, pobreza, novas práticas alimentares estruturadas no mundo do consumo e suas implicações nefastas para o sistema de saúde e a seguridade social., ${ }^{1,-4}$ Segundo Oliveira, o custo da obesidade para o Sistema Único de Saúde (SUS) em 2011 foi de quase meio bilhão de reais. ${ }^{5}$ A obesidade mórbida já atinge 1,5 milhão de adultos brasileiros e o seu custo foi proporcionalmente 4,3 vezes maior que o da obesidade, que afeta $12,5 \%$ dos homens e $16,9 \%$ das mulheres do país. Aliás, a prevalência da obesidade aumentou rapidamente nas últimas décadas, caracterizando uma epidemia, com incremento de $2,8 \%$ para $12,4 \%$ nos homens e de $8 \%$ para $16,9 \%$ entre as mulheres.

O enfrentamento dessa questão impõe a adoção de uma visão transdisciplinar para o problema e as alternativas para seu manejo não podem ser pensadas somente pela responsabilização do cidadão e pelo controle individual da alimentação através de dietas. A obesidade, encarada como problema de saúde coletiva, situa-se muito além dos limites do campo das Ciências da Saúde ou do saber técnico da Nutrição, apresentando-se como um grave problema político, ideológico e econômico. Assim, os profissionais de saúde têm um papel fundamental nessa discussão, em particular, no que concerne a possibilidade de compreensão deste fenômeno, ultrapassando o pensar biomédico.

A obesidadeé um assunto que interessa ao conjunto da sociedade. Suas implicações se estendem aos campos da Economia e da Política, repercutindo sobre a formulação das políticas públicas nas áreas da Educação e Saúde. Seu enfrentamento impõe profundas discussões sobre interesses oriundos do mercado, indústrias de alimentos e farmacêuticas, indústria da beleza e medicina estética, publicidade, vigilância sanitária, meios de comunicação e o próprio campo da ciência. Soluções substantivas, portanto, não acontecerão apenas pelo monitoramento permanente do comportamento saudável dos indivíduos, pelo autocontrole da alimentação cotidiana e com regularidade de exercícios físicos. Pelo contrário, a complexidade do problema nos impõe a necessidade de analisar as inúmeras variáveis que compõem essa equação, o que passa, necessariamente, pelo resgate de seus antecedentes históricos.

Entendemos que o problema da obesidade precisa ser compreendido em suas diferentes dimensões biológicas, genéticas, ambientais e bioquímicas, presentes no âmbito das Ciências da Saúde ou da Natureza. Natureza e Cultura formam par indissociável e devem ser articulados sempre diante de fenômenos complexos, que exigem abordagens transdisciplinares. Assim, não podemos deixar de lembrar que a obesidade também é um problema de ordem social, cultural e subjetiva, que influencia a construção da identidade individual e afeta a saúde psíquica dos que contam com peso a mais, dos que são julgados de forma negativa e depreciativa por familiares, amigos, conhecidos, inclusive por profissionais de saúde.

Trazemos aqui alguns elementos relativos às representações sobre o corpo gordo construídos a partir de um breve olhar para o passado. Devido à limitação de espaço, buscamos tão somente a aproximação ao tema pela via da subjetividade a partir, em particular, de Vigarello, ${ }^{6,7}$ autor dedicado a estudos que contribuem para a compreensão dos sentidos associadas ao corpo ao longo da história, e de Goffman, ${ }^{8,9}$ que trabalha a partir do conceito de estigma, essa espécie de marca de valor negativo entranhada numa diferença socialmente construída. O presente estudo se justifica por trazer à tona o processo em curso de moralização e estigmatização do qual são alvo as pessoas que se encontram acima do peso corporal idealizado nas sociedades modernas.

\section{Num relance de olhar, o passado...}

Os estudos e comentários acerca das pessoas gordas se confundem com a história do pensamento ocidental. Basta lembrar que o tema sempre esteve presente entre nós, apresentando variados sentidos em diversos momentos do passado e distintos do que se registra nos dias atuais.

Sobre a obesidade, afirma Poulain: "Os médicos gregos já se interessavam por ela e a consideravam como uma enfermidade desagradável" ${ }^{10}$ Segundo Vigarello, desde Hipócrates, a obesidade é vista de forma pejorativa, como algo que é diferente da carne, pois “(...) a gordura do atleta é diferente da gordura do gordo, enquanto uma se dobra sobre a carne a segunda se dobra sobre a banha". ${ }^{6}$ Entre os romanos, também encontramos o comentário de Caelius Aurelianus, que engloba a gordura como supérflua carnis, que causa lentidão de 


\section{Artigo de revisão}

movimentos e debilidade; esse médico e escritor sobre tópicos relacionados às doenças preconizava para tal condição o uso de purgativos, além da atividade física. Poulain aponta que Galeno, por seu turno, “(...) recomendava às pessoas obesas a luta e os exercícios físicos violentos para fazer o corpo sobrecarregado voltar a um estado moderado". ${ }^{10}$

Georges Vigarello, na obra "As metamorfoses da gordura", mostra as transformações no modo de perceber e significar o corpo gordo ao longo de diferentes séculos. ${ }^{6}$ Desde os glutões medievais até os obesos da atualidade, as formas de representar e tratar a gordura passaram por várias alterações. No universo medieval, por exemplo, em contraposição à escassez de alimentos e a fome, o gordo se impõe com poder de seduzir e impressionar ao sugerir abundância, riqueza e saúde.

O universo medieval - quando do esgotamento dos solos, insuficiência no armazenamento, lentidão e precariedade no transporte - sofreu cerca de 1.300 crises de abastecimento de alimentos. Esse período, marcado por fome e peste gerou, ao mesmo tempo, no imaginário social, a idealização de um mundo de fartura e de abastecimento seguro dos alimentos. ${ }^{11}$ Símbolos desse mundo maravilhoso, "países da fartura" são descritos como paraísos na Terra, repletos de especiarias, carnes gordas e pão branco, além de vinho e cerveja. O país imaginário da "Cocanha" traduz o sonho medieval: um lugar de fartura e acúmulo. Se o período é de fome extrema, a saída é a fantasia; e o pecado da gula é relativizado. Saúde, então, significava barriga bem cheia.

Várias gorduras coexistiam: uma era a da doença por suas frouxidões líquidas; outra por seus extremos inquietantes; uma terceira gordura era a da saúde, pela força aparente que transmite. Esta talvez seja a mais importante posto que - filha da ascendência, ligada ao prestígio dos acúmulos, tolerante com a comilança desbragada - aumentava poder e segurança. Todavia, nada ou quase nada se falava sobre a transformação da condição de gordo para a de muito gordo. Nada se dizia de sua franca disparidade. A "ampla e robusta corpulência" de Guilherme, o Conquistador, no século $\mathrm{XI}$, por muito tempo foi vista como sinal de vigor antes de se inverter e virar marca de fraqueza. ${ }^{6} \mathrm{O}$ corpo farto era sinal de poderio e distinção, numa época em que a fome predominava.

Nos séculos centrais da Idade Média, foram produzidas algumas importantes mudanças na representação do "gordo". Críticas à gordura comum aumentaram, ainda que de forma difusa. Pressões, inicialmente instaladas no âmbito do clero e suas pregações que valoriza- vam autocontrole e contenção, levaram à compreensão do corpo medieval atravessado por forte tensão que transitou entre polos opostos: da fome, pestes, mortificação da carne, contenção e ascetismo monásticos; à gula, fartura eluxúria dos monges em vida religiosa. Em contexto de profunda escassez, a alimentação era vista como uma das principais fontes de prazer. ${ }^{12}$

A austeridade clerical, antes confinada aos mosteiros e claustros, difundiu-se nas preces e nos sermões dos séculos XII e XIII bem no coração das cidades. Culpa, rejeição aos contornos corporais, vício e contensão dos excessos se destacam nessa oratória. Não é a estética que está no centro do debate, mas vício e pecado. $\mathrm{O}$ risco moral se sobrepunha. A transgressão medieval era, essencialmente, ardor e empolgação, e o corpo gordo, acima de tudo, vítima de paixão incontrolável. Paradoxalmente, o próprio clero que representava a glutonaria - muitas pinturas da época representam o pecado da gula utilizando imagens dos frades robustos e bem alimentados. ${ }^{11}$

Depois, vieram os médicos com a difusão de perigos da gordura, conformando outra cultura que se afirmou nos séculos centrais da Idade Média. Suas recomendações, antes reservadas à nobreza cercada de conselheiros, passaram a ganhar certa popularidade e se "generalizam" visando e efetivamente alcançando um público mais bem instruído. Seus textos não mencionavam "o gordo", mas sugeriam sinais de vigilância para os excessos. O gordo era visto como o "último" e o "insuportável" e os discursos referiam-se mais à espessura e atos do que formas e contornos. ${ }^{6}$ O gordo "médio" está ausente nas imagens e palavras. Apenas o "muito" gordo recebia atenção constante.

A corte medieval exerceu também forte influência cultural sobre o corpo por meio de seus costumes e valores, atenta ao refinamento, expressava restrições aos gordos e suas práticas cotidianas. A aparência cortesã já remetia a maior finura. As figuras do lanceiro e do cavaleiro exigiam habilidade e precisão de movimentos associadas à força e corpulência Vigarello. ${ }^{6}$ Nesse cenário, a ascendência e as atividades sociais ainda valorizavam o acúmulo alimentar. Somava-se a isso a destreza que só mesmo a estreiteza de flancos tornaria possível. É a mistura repetida de largo e estreito, do grande com o leve, uma maneira particular de valorizar o pesado associado ao vigor dos movimentos.

De maneira geral, nas cortes da Idade Média, o corpo feminino estava associado à delicadeza e à fragilidade de membros. O olhar altivo integrava-se ao físico vulnerável, esbelto e, ao mesmo tempo, carnudo. Também 
aqui a mistura de finura e vigor, de delicadeza e fartura. Para as mulheres, em particular, era mais acentuada a pressão pela aparência mais fina e, de forma geral, comprometidas com uma sociabilidade global: danças, maneiras à mesa, aparência, comportamento.

Nas imagens do século XV, com o uso da perspectiva, aparecem corpos com mais espessura e densidade. $O$ universo das imagens começou a ser dividido segundo as diferenças de porte e tamanho. Visto de outra forma, o volume corpóreo parece que passou a existir de outra maneira, sugerindo seus excessos, impondo seus "defeitos".

O contraste dos contornos sugere também a distinção social. Por exemplo, segundo Vigarello, numa ilustração de Gaston Phoebus, do século XV, aparecem primeiro os "ajudantes", homens do povo, valetes, batedores, assistentes diversos, de gestos animados e com vestimentas de lã. ${ }^{6}$ Em seguida, está o senhor e seu séquito, de gestos mais controlados, porte mais seguro, vestindo roupas de pele ou veludo. Os "ajudantes" em geral têm rostos roliços, são por vezes barrigudos, em oposição ao senhor e seu séquito de corpos esguios, rostos alongados, cinturas finas.

Outras ilustrações do século XV parecem evocar certas profissões valorizadas pela gordura: cozinheiros, padeiros, açougueiros com corpos nitidamente volumosos. Por sua vez, o senhor está instalado numa mesa alta, com utensílios e facas à sua disposição, consumindo pequenas porções e afastando o prato com as mãos em sinal de rejeição dos excessos. Nada mais cultural do que essa oposição entre o popular e o distinto. Associados a isso, o interesse e a necessidade do distanciamento, a codificação social, o que se repara nos corpos. Aí se reconhece, sobretudo, essa referência social em que o baixo popular seria associado ao gordo e o distinto superior, à leveza. É o olhar que discrimina e moraliza com base numa orientação social.

Todavia, nesse terreno de tensões, o prestígio da acumulação não cedeu às normas do clero, da medicina ou da corte. A ambiguidade relativa à fronteira entre o "gordo" e o inaceitável permaneceu ainda por muito tempo.

Somente ao final da Idade Média, começaram a aparecer volumes e contornos nas figuras dos afrescos, sinalizando a atenção aos desenhos mais precisos dos corpos e delineando os caminhos da identificação e estigmatização dos excessos. Essa iconografia revela, sem dúvida, um novo olhar para a gordura: o realismo impondo-se nas imagens.

$\mathrm{Na}$ Renascença, o foco da crítica ao gordo mudou.
Os "cuidados" com o gordo também se acentuaram, passando a se concentrar nos regimes e na contenção das carnes por meio de cintas e corpetes. A gordura corporal passou a ser sinônimo de lerdeza, o aumento de peso posto como um "atraso", uma inadaptação ao novo ritmo do mundo. A crítica ao que é "pesado" ou "enorme" assumiu contornos mais rígidos no Século XVI. A preguiça vira uma espécie de peste do pensamento humano. A gordura associada à lerdeza, preguiça e improdutividade parece tomar conta do pensamento do momento. A Modernidade apegou-se, sobretudo, à eficácia e criticou a moleza.

A ruptura mais profunda e significativa veio com a consolidação da Europa Moderna. Evidenciam-se o julgamento moral dos "gordos e preguiçosos", o denegrir e zombar das "fuças roliças", das "grandes e gordas criaturas", dos "rostos vermelhos e panças enormes". $\mathrm{O}$ "grande" passou à condição de "gordo", "arriado" e "indolente".

O início do século XIX trouxe também questões bastante próximas às que se colocam hoje nos estudos sobre a obesidade. Na obra clássica de Brillat-Savarin, "La Physiologie du goût", estão indicadas quatro causas principais para esse problema:(a) a natureza ou "disposição" dos indivíduos, ou a predestinação do organismo a produzir uma quantidade maior de gordura, o que hoje chamaríamos de predisposições genéticas; (b) a ausência de atividades físicas ou pouco exercício, propondo o aumento do gasto energético para restabelecer o equilíbrio; (c) os excessos ao comer e a má alimentação ou o uso de produtos que propiciam o ganho de peso; (d) o uso excessivo das farinhas que o homem usa em sua base de alimentação diária. ${ }^{13}$

Poulain chama a atenção para a criação dessa estrutura argumentativa relativa à "má alimentação" como causadora da obesidade, já no século XIX.10 O autor identifica, ainda, no filósofo inglês, David Hume (1711-1776), que sofria de obesidade, o primeiro a pensar o problema a partir de uma etiologia psicológica. Hume procura um médico quando percebe que, a partir do seu estado de espírito, vem a extinção do "ardor do desejo" e do prazer carnal intenso e que na depressão provocada pela perda deste ardor, surge um "apetite devorador", provavelmente causando o aumento de peso. Hume constrói "uma cadeia de causalidade entre um acontecimento psicológico e o desenvolvimento da obesidade" ${ }^{10}$ Trata-se, então, de uma primeira hipótese sobre as origens psicológicas da obesidade e, posteriormente, do estabelecimento da lógica formal que ancora o processo de sua medicalização. Durante o século XIX, 


\section{Artigo de revisão}

os progressos da medicina passaram pela localização das patologias no corpo, levando à pesquisa da causa biológica da obesidade. "O verdadeiro estatuto patológico da obesidade começa, portanto, quando se passa a considerar o tecido adiposo como o foco do problema da doença" ${ }^{10}$ É o início do conceito médico moderno de obesidade e, a partir deste momento, as ciências médicas passam a tentar evidenciar os processos anatômicos e fisiológicos que agem por trás do seu desenvolvimento.

\section{A beleza feminina no início do século $\mathrm{XX}$}

Para Vigarello, o início do século XX assiste a uma mudança radical da silhueta e dos padrões de beleza corporal, principalmente para as mulheres. ${ }^{7}$ Entre 1910 e 1920, os corpos se libertam e as formas se alongam, como se as linhas do corpo ganhassem autonomia e acompanhassem a profunda transformação social em curso. A mulher, que agora ingressa no mercado de trabalho, busca uma imagem de movimento e atividade por meio de uma elegância apropriada aos novos tempos de desenvoltura e liberdade. A atuação feminina no mundo do trabalho cria novos critérios estéticos e cuidados com o corpo. A cosmetologia é também rearticulada. A publicidade dos anos 1930 destaca a liberdade e a necessidade de se adequar à nova ordem estética que prega a vida ao ar livre, a ginástica e o bronzeado. São lançados inúmeros cremes e loções bronzeadoras que prometem destacar a cor da pele e a ação dos raios ultravioleta.

O corpo feminino começa a ser trabalhado e passa a exibir os signos da cultura física e da atividade esportiva, os músculos se tornam visíveis, elásticos, deixam de ser propriedade exclusiva do universo masculino. Os editoriais das revistas de beleza dos anos 1930 destacam "uma silhueta esbelta e esportiva, com membros finos e músculos sem gordura, e a figura enérgica e livre é hoje a imagem ideal da beleza feminina". 0 uso dos maillots destaca as formas e transforma os critérios de beleza, ressaltando qualidades e defeitos, fazendo com que a balança passe a fazer parte do cotidiano da mulher. Desde as primeiras décadas de século XX, o peso é decretado "elemento primordial da beleza feminina" e seu excesso jamais deve ser considerado como sinal de saúde; ao contrário, pode ser perigoso, provocar riscos sanitários e até a morte. A gordura se transforma em inimigo número um da elegância e da felicidade.

As medidas corporais tornam-se uma marca de encanto e os concursos de beleza popularizam esse novo padrão estético. Os concursos de miss se multiplicam no período entreguerras e fazem com que as modelos exibam seus corpos perfeitos difundindo a nova silhueta. A partir da Segunda Guerra, o imaginário acerca do corpo ideal passa a sofrer também grande influência da indústria do cinema. A "usina de sonhos" hollywoodiana cria temas, universos, heróis, hábitos, valores, difunde uma cultura e cria novas referências. Novos padrões de beleza são estabelecidos, novos produtos cosméticos e novos modismos são criados a partir de um mercado editorial que se expande e leva a novas "tendências", a diferentes lugares do planeta.

Segundo Vigarello, ${ }^{7}$ a grande originalidade desse novo dispositivo é fantasiar os critérios de beleza existentes. O cinema joga com os corpos, com a luz, com a tela, com os sentidos do espectador, deslocando-o no espaço e no tempo, criando novos gêneros estéticos, modelando os corpos e ajustando-os aos novos estilos. Um imenso sonho social é criado a partir desse novo padrão de beleza. Institui-se uma pedagogia de massa que pretende promover o belo a partir do próprio público, de cada um de nós, rico ou pobre, vivendo em maior ou menor desigualdade social, comprando linhas e mais linhas de produtos e serviços de toda ordem, incluindo atividade física, dietas, medicamentos, cirurgias... novos e inovadores a cada dia. O indivíduo agora é o responsável maior por seu próprio corpo e por sua própria beleza e não pode se negligenciar, pois um anônimo pode se transformar e, a partir de seu próprio mérito, tornar-se admirável. Trata-se de uma estratégia centrada no indivíduo - voluntarista, meritocrática e apresentada com ares democráticos - que faz da beleza dos astros e estrelas algo aparentemente possível e acessível a todos. A aparência passa a ser submetida a um controle operado pelo próprio sujeito, um exercício da vontade - ou da "força de vontade" - que tem como referência o imaginário sugerido nas telas.

O mercado de trabalho cada vez mais burocratizado e hierarquizado também valoriza a aparência e cobra dos sujeitos a adequação às novas regras. $\mathrm{O}$ mundo de competição, de concorrência no qual a beleza ajuda a conquistar e manter espaços, ao preço da eterna vigilância e da estrita soberania de si. "Uma convergência se impõe, aquela que concilia Estética e trabalho".

Os cuidados com o corpo se transformam em fonte de investimento e preocupação, esculpir a silhueta começa a se tornar um dever e a beleza é submetida a um trabalho de pensamento que busca afirmar a confiança em si. Segundo Vigarello, "o corpo é uma argila que se molda à vontade da cultura física e aos cuidados da beleza". A silhueta não se faz mais a partir dos artifícios 
do século XIX como as cintas. Trata-se agora de um controle rígido sobre o próprio corpo, com exercícios, vontade, determinação. É o início do processo atual de culto ao corpo magro e desprezo pela gordura: são os tempos lipofóbicos. Daqui por diante, a gordura cada vez mais se torna algo indesejável e nocivo. O corpo gordo passa a ser, cada vez mais, tratado como defeito físico e moral e as pessoas gordas estigmatizadas.

\section{A estigmatização das pessoas gordas nos dias atuais}

Cabe lembrar que "a magreza, até bem pouco tempo foi associada à doença, à melancolia e à esterilidade, e os corpos carnudos relacionados à saúde e fecundidade." ${ }^{10} \mathrm{O}$ corpo feminino que hoje é considerado "um pouco acima do peso" e, portanto, "fora do padrão de normalidade", no passado recente, era valorizado como um "violão", "cheinho" ou "roliço" e, em geral, extremamente sensual. Mesmo hoje, ainda há diferentes culturas que colocam o estado de obesidade como um padrão normal e, às vezes, até desejável. Todavia, a gordinha simpática e o volumoso bonachão, que no passado transitavam normalmente pela vida, hoje são alvos de críticas e de juízos de valor, pois a imagem do gordo é associada à pessoa que "não tem controle", "não tem limites", "vai além do necessário" e, portanto, não é uma pessoa confiável. Depreciados, desvalorizados são moralmente julgados e, em rito sumário, condenados: são estigmatizados.

A partir da significativa valorização do corpo magro de que temos conta, desde o início do século XX percebemos a ampliação do olhar negativo sobre o gordo e aprofundamento de sua estigmatização. Para Erving Goffman, ${ }^{9}$ um aspecto fundamental nas abordagens sobre o estigma reside na referência "aos sinais corporais com os quais se procurava evidenciar alguma coisa de extraordinário ou mau sobre o status moral de quem os apresentava". Esse caminho conceitual possibilita compreender o gordo como portador de atributo que o faz estranho, socialmente impuro, depreciado, renegado nas relações cotidianas. Para Goffman, ${ }^{8}$ o processo de estigmatização se instala na expectativa dos atores que vivenciam dadas relações sociais - ou seja, a gordura corporal não é, de per si, boa ou má, mas o olhar estabelecido pelos atores em relação é que imprime ao gordo a marca do indesejável e repugnante: “O estigma, nessa perspectiva, é uma relação entre atributo e estereótipo (o que sou/o que tenho - o que esperam de mim)". ${ }^{14}$

A título de exemplo, o estudo acerca de mulheres usuárias do SUS mostra que "pesam" sobre elas não ape- nas os quilos, mas também - e, de certo, principalmente - a discriminação firmada na aparência.

O estigma se traduz em olhares recriminadores, insultos, comentários jocosos e significa a impossibilidade de inserção no mercado de trabalho formal. O estigma da obesidade permeia as distintas esferas da vida das informantes do estudo, principalmente em suas relações interpessoais, sociais, familiares e de trabalho. Além disso, ele atinge a dimensão do própriogrupo das informantes, em relação a si mesmo e ao outro igualmente obeso. Percebemos que as informantes do estudo transitam entre vítimas e algozes do estigma da obesidade, seja como um mecanismo de projeção ou de proteção. ${ }^{14}$

Nessa linha, vale registrar que, no Brasil, o mercado de trabalho opera um tipo de "seleção" que traduz a lipofobia dominante. Um concurso recente para professores da Educação Básica no Estado de São Paulo rejeitou $25 \%$ dos candidatos por apresentarem quadro de obesidade. ${ }^{15}$ De 11.858 docentes aprovados e que passaram pela avaliação de saúde, 155 foram considerados inaptos nas perícias, sendo 39 (25\%) deles recusados por obesidade. Este caso é emblemático do tratamento estigmatizante dispensado aos obesos. Em outras áreas da vida profissional, como o comércio ou atendimento ao público, esta "seleção" é feita de forma dissimulada e naturalizada; basta andar pelos shoppings de qualquer cidade para perceber que não há vendedoras acima do peso.

Esse modo de discriminação faz parte de toda a história das pessoas gordas sendo, nos dias atuais, particularmente reforçada e reiterada por meio dos processos de medicalização da vida cotidiana e estetização da saúde, ${ }^{16}$ nos quais o que é considerado saudável passa a ter relação direta com a forma física, nomeadamente, magra. O processo de estetização da saúde produz o exagero no papel dos parâmetros estéticos como definidores do que é considerável adequado ou saudável, levando a valorização excessiva e até mesmo obsessiva dos cuidados com o corpo, aparência e alimentação. A magreza passa a ser vista como símbolo de competência, força de vontade, sucesso em todas as esferas da vida; representa o controle da impulsividade e o império da razão onde qualquer comer a mais passa - no "vapt-vupt" da correria cotidiana, cada vez mais fast - a significar "compulsão alimentar". Em outras palavras, o corpo magro se torna o principal referencial de beleza e o parâmetro da vida saudável, possibilitando sua maior inserção no mundo do trabalho e no mercado sexual, 
ampliando suas chances de ascensão social. O corpo gordo é o seu oposto.

Em tempos de discursos a favor do multiculturalismo, da diversidade étnica e social e do respeito às diferenças de gênero, o estigma contra a obesidade segue crescente. Existem diferentes grupos que atuam contra os preconceitos de raça, cor, etnia, gênero e classe social e que, na vida cotidiana, muitas vezes, são preconceituosas com os obesos; isso, sem deixar de lado a discriminação entre os que não são ou que não se veem magros. E as camadas de estigma se acumulam se a pessoa for negra, pobre, nordestina, gay e gorda. Esta estigmatização largamente disseminada gera mais e mais problemas e não aponta para uma solução.

Não podemos pensar o problema da obesidade sem considerar a responsabilidade da indústria de alimentos, das vendas crescentes de refrigerantes e bebidas alcoólicas, das redes de fast food e do papel dos produtos ultraprocessados - apresentados como comida e conformando um mundo obesogênico. A praticidade, o baixo custo e a facilidade de aquisição destes produtos, em contraposição à alimentação mais sadia, os problemas ligados ao controle do processo industrial e os conflitos de interesses na produção de alimentos e de conhecimentos científicos precisam ser pensados e enfrentados.

Para enfrentar a problemática da obesidade e do excesso de peso, é preciso tomar o indivíduo como efeito desses movimentos subjetivos que não estão desvinculados da cultura e da política que se articulam em torno do consumo irrefreável característico do nosso tempo. Ressaltar os paradoxos pertinentes à forma de ver o corpo gordo ao longo da história é um aspecto relevante para não cairmos na ingenuidade de acreditar que mudar hábitos alimentares e alcançar o desejado emagrecimento da população é uma tarefa exclusivamente relacionada à força de vontade do próprio indivíduo. Entender o problema apenas na sua perspectiva biomédica, centrada nos processos patológicos e fisiológicos, ignorando toda a construção subjetiva, responsabilizando o indivíduo, culpando-o por suas escolhas e esquecendo os interesses do mercado talvez não seja a melhor alternativa que dispomos, mas somente a mais fácil.

\section{Referências}

1. Prado SD, Freitas RF, Ferreira FR, et al. Alimentação, consumo e cultura. Série Sabor Metrópole. Curitiba: CRV; 2013.

2. Baudrillard JA. A sociedade de Consumo. Lisboa: Edições 70; 2005.

3. Bauman Z. Vida para consumo: a transformação das pessoas em mercadoria. Rio de Janeiro: Jorge Zahar; 2008.

4. Giddens A. Modernidade e identidade. Rio de Janeiro: Jorge Zahar; 2002

5. Oliveira ML. Estimativa dos custos da obesidade para o Sistema Único de Saúde do Brasil [doutorado]. Brasília: Faculdade de Ciências da Saúde; 2013.

6. Vigarello G. As metamorfoses da gordura. Petrópolis: Vozes; 2012.

7. Histoire de la beuté. Le corps et l'art d'embellir de la renaissance à nos jour. Paris: Éditions du Seiu; 2004.

8. Goffman E. 1988. Estigma: notas sobre a Manipulação da Identidade Deteriorada. Rio de Janeiro: Livros Técnicos e Científicos; 1988.

9. Manicômios, prisões e conventos. São Paulo: Perspectiva; 1987.

10. Poulain JP. Sociologia da obesidade. São Paulo: Senac; 2013.

11. Quellier F. Gula: história de um pecado capital. São Paulo: Senac; 2011.

12. Le Goff J, Truong N. Une histoire du corps au Moyen Âge. Paris: Liana Levi; 2003.

13. Brillat-Savarin JA. A fisiologia do gosto. São Paulo: Cia das Letras; 1995

14. Pinto MS, Bosi MLM. Muito mais do que pe(n)sam: percepções e experiências acerca da obesidade entre usuárias da rede pública de saúde de um município do Nordeste do Brasil. Physis 2010;20(2):443-457.

15. Folha de São Paulo. Professores obesos são $25 \%$ dos barrados em concurso de São Paulo. Folha de São Paulo Caderno Cotidiano (São Paulo). 2014 May 25. Brazil.

16. Ferreira FR, Freitas PMSS, Wollz LEB. O culto ao corpo, a estetização da saúde e o papel do nutricionista. In: Prado SD, Freitas RF, Ferreira FR, et al. Alimentação, consumo e cultura. Série Sabor Metrópole. Curitiba: CRV; 2013. Capítulo 1. 